\title{
MULTI-SENSOR NETWORK FOR LANDSLIDES SIMULATION AND HAZARD MONITORING - DESIGN AND DEPLOYMENT
}

 \\ Xiaohua $^{\mathrm{a}, \mathrm{b}}$, Wang Weian ${ }^{\mathrm{a}, \mathrm{b}}$, Shen Yunzhong ${ }^{\mathrm{a}, \mathrm{b}}$, Guan Zequn ${ }^{\mathrm{a}, \mathrm{b}}$, Li Rongxing ${ }^{\mathrm{b}, \mathrm{c}}$ \\ a Department of Surveying and Geoinfomatics, Tongji University, P.R.China.-(hb@tongji.edu.cn) \\ ${ }^{\mathrm{b}}$ Centre for Spatial Information Science and Sustainable Development, Tongji University, P.R.China \\ ${ }^{c}$ Mapping and GIS Lab, The Ohio State University- 1i.282@ous.edu
}

KEY WORDS: Landslides, Multisensor, Acquisition, Monitoring, Networks

\begin{abstract}
:
This paper describes a newly developed multi-sensor network system for landslide and hazard monitoring. Landslide hazard is one of the most destructive natural disasters, which has severely affected human safety, properties and infrastructures. We report the results of designing and deploying the multi-sensor network, based on the simulated landslide model, to monitor typical landslide areas and with a goal to predict landslide hazard and mitigate damages. The integration and deployment of the prototype sensor network were carried out in an experiment area at Tongji University in Shanghai. In order to simulate a real landslide, a contractible landslide body is constructed in the experiment area by $7 \mathrm{~m} * 1.5 \mathrm{~m}$. Then, some different kind of sensors, such as camera, GPS, crackmeter, accelerometer, laser scanning system, inclinometer, etc., are installed near or in the landslide body. After the sensors are powered, continuous sampling data will be generated. With the help of communication method, such as GPRS, and certain transport devices, such as iMesh and $3 \mathrm{G}$ router, all the sensor data will be transported to the server and stored in Oracle. These are the current results of an ongoing project of the center. Further research results will be updated and presented in the near future.
\end{abstract}

\section{INTRODUCTION}

Landslide hazard is one of the most destructive natural disasters, which has severely affected human safety, properties and infrastructures. Traditionally, to monitor landslide and avoid human and properties loss, $3 \mathrm{~S}$ technique has been successfully applied in landslide research (Tan et al., 2003). However, landslide is a complicate system. The traditional terrain data sources, such as slope, aspect, land cover etc., which are generated by $3 \mathrm{~S}$ technique, could not represent the whole geometrical and physical characteristics of landslide. Some other data sources, such as geological data, are also playing important roles in landslide study. Moreover, landslide is a dynamic and moving system, while mutative events, such as precipitation and earthquake, will usually

\footnotetext{
* Corresponding author.
}

provoke the landslide in a short time. Therefore, meteorological and external mechanical data are also vital for landslide research. Simulating the landslide related data is an important work in landslide study. Therefore, sensor networks are always used to monitor the landslide.

A sensor network is a communication infrastructure or group of specialized transducers to monitor, record and respond to any phenomena or diverse locations (Rahman, 2010). According to the style of sensor, the sensor network established in our project can be divided into wireless sensor network and wired network, or geospatial sensor network and non-geospatial sensor network (Verdone et al. 2008, Stefanidis and Nittel., 2004). Due to the large count of sensor used in landslide monitoring, the relationship among sensors 
is complicated. Therefore, it is necessary to build and create the sensor network for landslide monitoring.

3D digital landslide simulation based on multi-sensor network is a new method to analyse landslide numerically, visually and repeatedly (LI Xianhua et al., 2003). It constructs the landslide body by certain scale and under geological condition. Then spatial and non-spatial sensors are placed in or near the landslide body to observe and monitor the whole landslide. By sensors' output, not only terrain data, such as imagery, DEM, GPS etc., but also the mechanical, geological, pedological, meteorologic data will be collected and recorded. Combining the terrain data with non-spatial data, mechanical, geological, pedological, meteorologic data, the status of the landslide body can be directly expressed in 3D landslide model. Moreover, some high frequency sensors, such as high-speed camera and accelerometer, will record the evolvement of landslide in incredible detail. Therefore, 3D digital landslide simulation provides researchers a direct and dynamical way to observe the landslide status, analyze mechanical parameters of soil and rock, determine the rules and relationship between landslide and corresponding environmental key factors, and accumulate evolved knowledge of landslide. It can be used both in landslide research and prediction.

In this paper, we report the results of designing and deploying the multi-sensor network for landslide monitoring based on simulated landslide model, for the purpose of predicting landslide hazard and mitigate damages. The integration and deployment of the prototype sensor network were carried out in an experiment area at Tongji University in Shanghai. After the system is tested, it will be modified and moved to a larger scale slope in Wenchuan, where landslide hazards are severe and frequent problems. Currently, the landslide body was built in Tongji campus and more than ten kinds of sensors are installed in or near the landslide body.

\section{FLOWCHART OF THE LANDSLIDE SIMULATION AND HAZARD MONITORING PROJECT}

There are totally three parts in our landslide monitoring project. It can be seen in Figure 1. The first one is the establishment of the multi-sensor network. During this step, a scaled-down landslide body is also designed and deployed in order to provide location and area for the sensor network installation. The second part is real-time data acquisition and landslide monitoring. All the sensors are powered to generate the sensors' observations and then, transferred to a database to record the real-time data. The last step is to manage and analyze the sensor data to evaluate the landslide status by changing the precipitation and other landslide triggering factors. The first two parts have been finished in our project currently.

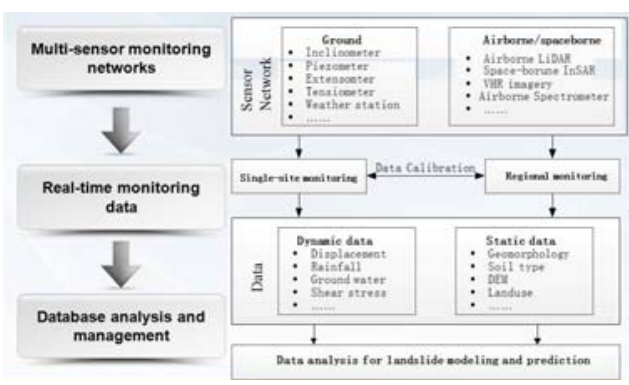

Figure 1. Flowchart of the landslide simulation and hazard monitoring project

3. SCALED DOWN LANDSLIDE BODY SIMULATION AND MULTI-SENSOR MONITORING NETWORK

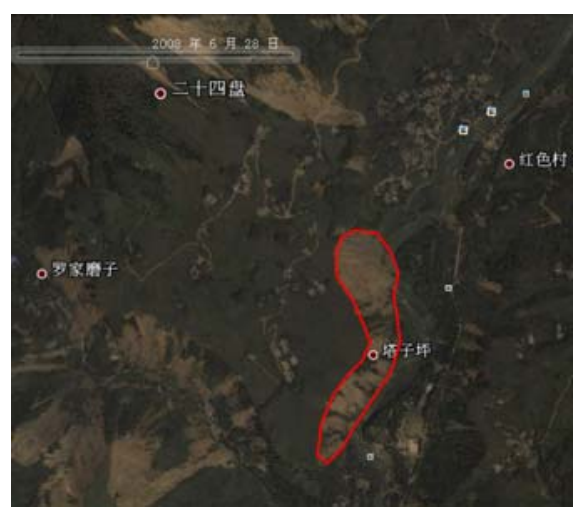

Figure 2. Hongkou landslide area in Sichuan Province

In our project, we are about to simulate the real landslide in Hongkou Town, Dujiangyan City, Sichuan. After Wenchuan earthquake, several landslide events have been happened. Therefore, it is an ideal landslide research case for our project. 
In our project, a scaled down landslide will be designed and created to install the sensor work.

\subsection{Simulation of landslide body}

Simulation of landslide body is carried out to simulate the real landslide body based on the similar characteristics such as hill slope and soil features with Hongkou landslide. The purpose of the landslide body simulation includes, an imitation of landslide monitoring sensor network based on the space/air/ground - borne sensor; a test of the sensor parameters such as level of sensitivity, accuracy, and applicability induced by rainfall; an initial landslide sensor network performance evaluation for the synergistic observation of sensors, correlation of the multi-source data, real time monitoring, and the visualization of the remote sensing data.

The landslide platform is located at the surveying and mapping experiment department, Tongji University, Shanghai. The space for the platform is $15 \mathrm{~m}$ long and $8 \mathrm{~m}$ wide, thus the landslide platform is designed as $7 \mathrm{~m}$ by $1.5 \mathrm{~m}$. To better simulate the 20-40 degrees slope angle of the landslide mass in Hongkou Town, the landslide platform is designed into three parts, while the slope angle of each part is 30 degree, 15 degree, and 5 degree respectively. The layout of the landslide platform is shown as Figure 3.

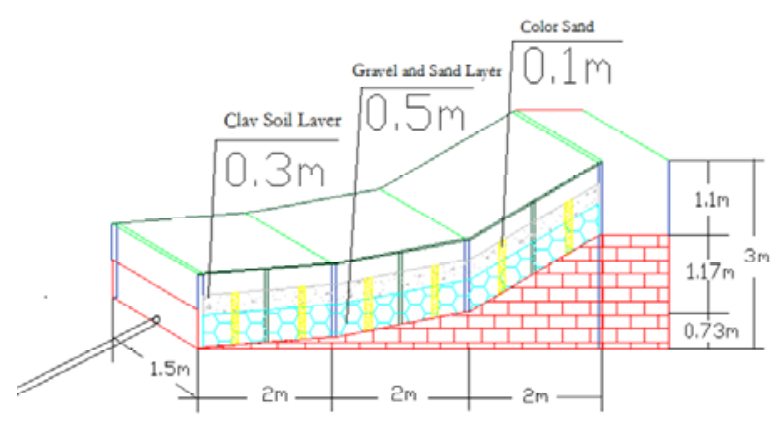

Figure 3. The layout of the simulated landslide platform

The platform is built with red bricks as its foundation, and the tempered glass of $2 \mathrm{~cm}$ width to contain the landslide mass. Steel frame is installed and fixed around the tempered glass for the security purpose. Each part of the landslide platform is $2 \mathrm{~m}$ in length, and $1.5 \mathrm{~m}$ in width. With the three angles of 5 degree, 15 degree and 30 degree, the highest part of the platform is thus $3 \mathrm{~m}$. There is a terrace of $3 \mathrm{~m}$ by $1.5 \mathrm{~m}$ by $1 \mathrm{~m}$ at the rear of the platform for settling down the transducers of the sensor network. Water supply system is mounted on the steel frame to simulate the rainfall environment for the landslide test, and a drainage system is designed to deal with the waste water.

To simulate the dense gravel and loose soil characters of Hongkou Town, the landslide mass is divided into two layers: the $0.5 \mathrm{~m}$ height gravel and sand layer at the bottom, and the $0.3 \mathrm{~m}$ height clay layer at the top. The gravel and sand layer is composed of clay, sand, and gravel with a proportion of 1:1:5, while for the clay layer, clay and sand with a proportion of 1:3. To monitor the internal slide of the landslide mass, a $0.1 \mathrm{~m}$ in diameter color sand bar is arranged at outer side of the tempered glass every $1 \mathrm{~m}$.

\subsection{Landslide monitoring sensors distribution}

In order to observe al and physical parameters of landslide body, a spatial and non-spatial sensor network was built to measure the unstable factors that might potentially trigger the landslide. In addition, it provides help to understand the evolution of mass movements, and to offer a reliable prediction regarding the future behavior of the landslide. As a result, this spatial and non-spatial sensor network is designed as a real-time system for a monitoring at different stages of landslide processes. The name, count and its monitor target of sensors and instruments adopted in this paper are listed in table 1. The horizontal and Longitudinal distribution of sensor are shown in Figure 4 and Figure 5.

\begin{tabular}{l|c|c}
\hline Name & Count & Monitor target \\
\hline $\begin{array}{l}\text { Wireless Video } \\
\text { Surveillance }\end{array}$ & 3 & $\begin{array}{c}\text { Total status of } \\
\text { landslide }\end{array}$ \\
\hline $\begin{array}{l}\text { Wireless Temperature and } \\
\text { Humidity Sensor }\end{array}$ & 1 & $\begin{array}{c}\text { Temperature and } \\
\text { humidity }\end{array}$ \\
\hline Crackmeter & 1 & Surface crack \\
\hline Drilling Dynamometer & 1 & $\begin{array}{c}\text { Pressure of mass } \\
\text { movement }\end{array}$ \\
\hline Anchor Dynamometer & 1 & Tensile stress \\
\hline $\begin{array}{l}\text { Large Range } \\
\text { Displacement Meter }\end{array}$ & 1 & $\begin{array}{c}\text { Movement of } \\
\text { certain area }\end{array}$ \\
\hline GPS & $1+1$ & $\begin{array}{c}\text { Ground } \\
\text { displacement }\end{array}$ \\
\hline $\begin{array}{l}\text { High-resolution Network } \\
\text { Cameras }\end{array}$ & 1 & $\begin{array}{c}\text { Surface failure } \\
\text { movement }\end{array}$ \\
\hline
\end{tabular}




\begin{tabular}{l|c|c}
\hline Piezometers & 8 & Pore-water pressure \\
\hline Inclinometer & 1 & Movement in depth \\
\hline Pluviograph & 1 & Ground-water level \\
\hline Accelerometer & 2 & Ground acceleration \\
\hline $\begin{array}{l}\text { 3D Laser Scanning } \\
\text { System }\end{array}$ & 1 & DEM \\
\hline Weather Station & 1 & $\begin{array}{c}\text { Temperature, soil } \\
\text { humidity, rainfall } \\
\text { intensity etc. }\end{array}$ \\
\hline
\end{tabular}

Table 1. The equipment used for landslide monitoring caused by external force

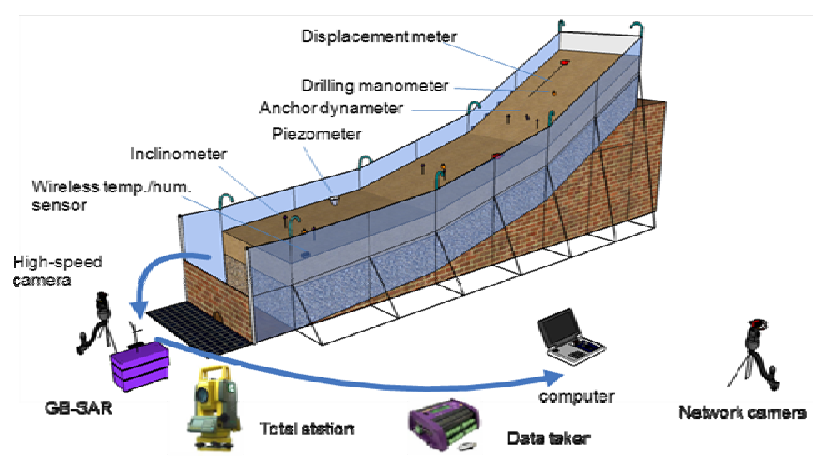

Figure 4. Horizontal sensor distribution in or near the landslide body

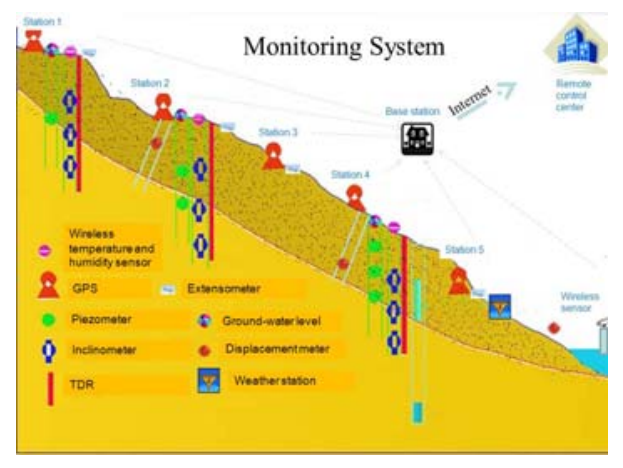

Figure 5. Longitudinal distribution of sensors

In detail, the layout of this spatial sensor network aims at 5 observation factors. First, it provides a real-time monitoring of displacements. This is fulfilled through displacement meter measuring displacement along the landslide surface and inclinometers measure ground displacement at the depth of the landslide. Also, a ground-based SAR (GB-SAR) was settled in front of the landslide body so as to estimate displacements from interferometric characteristics of SAR measurements. Second, the system focuses on a monitoring of ground water level change. This is completed by piezometer which measures pore water pressure inside the landslide body. Third, a total station was used to capture the landslide geometry such as slope and distance. Fourth, anchor dynameter and drilling manometer provide measures of forces vertical and parallel to surface movement. Finally, a wireless temperature and humidity sensor, combined with the weather station, was included to monitor the in-situ conditions such as temperature, humidity and rainfall intensity. It should also be noticed that a high-speed camera was used to capture the moment of landslide failure.

Most of the monitoring data was collected in the Data Taker due to its maneuverable. Some other sensors, such as accelerometer, Inclinometer and wireless network camera, were collected by other methods or devices. The procedure of data collection and transportation will be introduced in Section 4 of this paper.

\section{DATA COMMUNICATION AND STORAGE}

The data captured from all the sensors will be used to evaluate the status of the landslide body, thus the data should be transferred from the field to database initially. In our experiment, the simulated landslide body is located in the old Surveying Building at Tongji University, and the database(Oracle 11g) is built in the new Civil Engineering Building, and therefore, we need to transport the sensor data to the database.

In our experiments, all the sensors could be divided into three types: narrowband high frequency sensors(eg: Accelerometer, up to $80 \mathrm{HZ}$ ), narrowband low frequency sensors(eg: Large range displacement meter) and broadband sensors(eg wireless video surveillance). In order to reduce the influence of transportation of these sensors, different ways of communication are employed. The sketch of data communication for landslide monitoring is shown in Figure 6. 


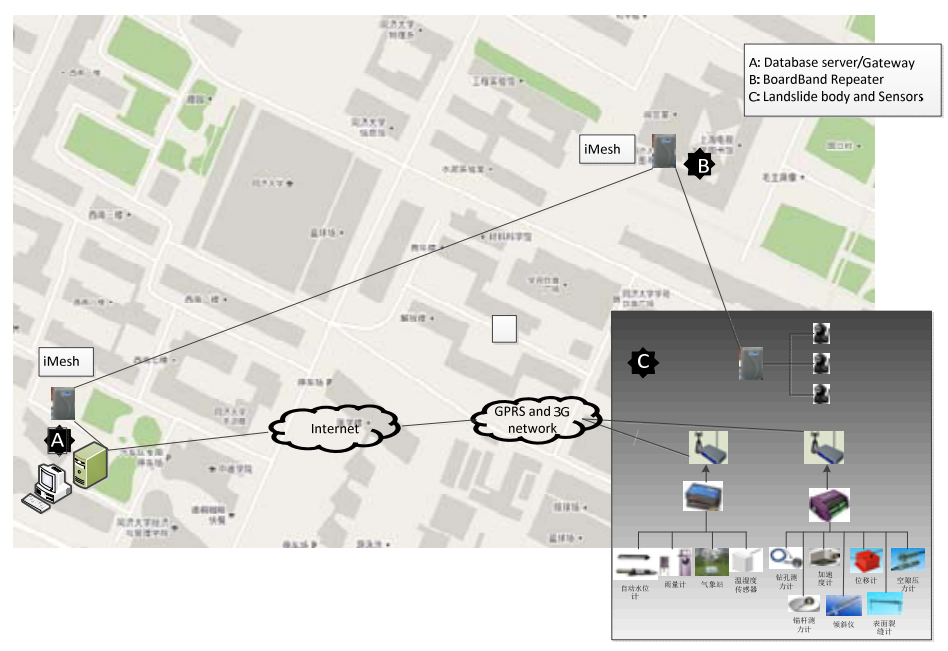

Figure 6. Diagram of sensor data communication

\subsection{Narrowband data communication}

3G and GPRS methods are firstly used to transport the narrowband sensor data, when GPRS method is used to transport the data captured by Data Taker and 3G method is used to transport the data captured by serial port, Ethernet and some other methods. With the help of $3 \mathrm{G}$ and GPRS network, public Internet, narrowband sensor data are transported from sensor to a certain port of database server. The communication speed of $3 \mathrm{G}$ and GPRS can reach to $350 \mathrm{k} / \mathrm{s}$ and $30 \mathrm{k} / \mathrm{s}$, which is enough for narrowband data transportation.

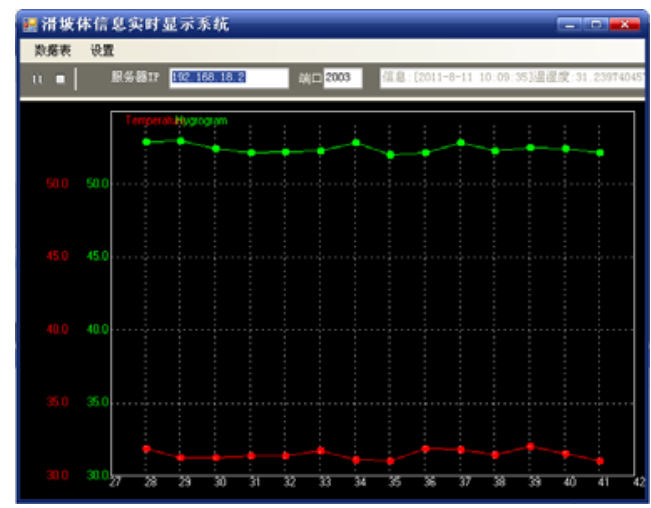

Figure 7. Client software for narrowband sensor network data communication
Client software (See figure 7) is always running to monitor port status and data stream. In our experiment, port 2002 and 2003 of database server are used for data communication using TCP protocol. Port 2002 is used to maintain the narrowband high-frequency data and port 2003 is used to capture the narrowband low frequency data. Once the sensor data has been seized by client software, original sensor data will be divided and then stored in Oracle database.

\subsection{Boardband data communication}

Another important kind of real time data is the video captured by camera. In our experiment, two kinds of camera are used to monitor the whole status of landslide body, high-resolution and standard-resolution camera. The data volume for high-solution and standard resolution camera can be reached to $8 \mathrm{M} \backslash \mathrm{s}$ and $2 \mathrm{M} \backslash \mathrm{s}$. Therefore, narrowband channel cannot be used to transport video data. Some special instruments, such as iMesh, are hired to establish a boardband channel for video data communication.

\section{CONCLUSION}

From the current establishment of sensor network for landslide monitoring, we have finished the following work and got some conclusions:

i. A scaled-down landslide body was built at Tongji 
University to simulate the real landslide. The geological and topographical characteristics of the landslide body are similar with Hongkou landslide.

ii. Different kinds of sensors are installed in landslide body which will help us generate abundant observations for landslide analysis.

iii. By using 3G, GPRS and boardband communication methods, all the observations are transferred to database server in real-time.

In the near future, we will start the work for landslide key factor analysis and landslide status evaluation on the simulation landslide body. In addition, more landslide detail, such as rock crack, megalith, etc., will be simulated in landslide body to accurately describe the real landslide area. Then, by using the sensor data and empirical landslide model and physical landslide model, a series of landslide systematic tests will be conducted by changing the precipitation and other landslide triggering factors. Thereafter, the developed technology will be deployed in a real landslide environment in the west mountainous region in China.

\section{ACKNOWLEDGEMENT}

We appreciate the support from 985 National Education fund and Kwang-Hua fund for College of Civil Engineering, Tongji University.

\section{REFERENCES}

Kazi Chandrima Rahman. A Survey on Sensor Network. Journal of Computer and Information Technology(JCIT), ISSN 2078-5828.

LI Xianhua, Lin Hui, Gong Jianhua, et al. 2003. Research and Dig ital Simulation about Digital Landslide Motion. Geo-Information Science. 9(3), pp36-41.

Stefanidis and Nittel (Eds.), 2004. GeoSensor Networks, CRC Press, Boca Raton, FL (296 pages).

Tan Debao, Zhang Yu, Sun Jiabing.2005 Real 3D Modeling of Landslide. Journal of Yangtze River Scientific Research Institute. 22(6). pp67-70.

Verdone, R., D. Dardari, G. Mazzini and A. Conti (2008), Wireless Sensor and Actuator Networks, Academic Press/Elsevier, London. 